\title{
Finalists are announced for The BMJ Awards 2016
}

\section{Zosia Kmietowicz, The BMJ}

The clinical leadership teams that have made the shortlist for The BMJ Awards 2016 cover a range of subjects, including reconfiguring ophthalmology services in Leeds, improving heart health in Bradford, and restructuring diabetes care in Portsmouth to ensure that patients access the right specialist care.

Now in their eighth year, the awards have this year attracted more than 300 entries, from which about 70 have been shortlisted. Four new categories are included in the 2016 awards: anaesthesia, dermatology, neurology, and prevention.

Next month the shortlisted teams will present their projects to a face to face judging panel, which for the first time will include a patient representative.

The winners will be announced on 5 May at the Park Plaza Westminster Bridge, London.
Shortlisted teams in the diabetes category cover many areas of disease management, including raising the standard of research into diabetes in pregnancy, improving outcomes in children with diabetes through peer support and engagement with schools, using technology to improve blood glucose control, and increasing awareness and diagnosis of monogenic diabetes. The headline sponsor for The BMJ Awards is MDDUS (Medical and Dental Defence Union of Scotland), and category sponsors include Macmillan, Leo Pharma, Public Health England, the BMA, the General Medical Council, and the Faculty of Medical Leadership and Management.

For a list of finalists see thebmjawards.com. The full list of categories is given in the box. 


\section{Categories for The BMJ Awards 2016}

Anaesthesia Team

Cancer Care Team

Cardiology Team

Clinical Leadership Team

Dermatology Team

Diabetes Team

Education Team

Gastroenterology Team

Innovation into Practice Team

Neurology Team

Palliative Care Team

Prevention Team

Primary Care Team

UK Research Paper

Lifetime Achievement Award 